\title{
The nexus of gut microbiota, diet, and health
}

\section{Sajal Bhattarai, Srinivas Janaswamy*}

Department of Dairy and Food Science, South Dakota State University, Brookings, SD 57007, USA

${ }^{*}$ Corresponding Author: Srinivas Janaswamy, PhD, Department of Dairy and Food Science, South Dakota State University, Brookings, SD 57007, USA

Submission Date: December 24 ${ }^{\text {th }}, 2021$; Acceptance Date: February $4^{\text {th }}, 2022$; Publication Date: February $9^{\text {th }}, 2022$

Please cite this article as: Bhattarai S., Janaswamy S. The nexus of gut microbiota, diet, and health. Functional Food Science 2022; 2(2): 47-63. DOI: https://www.doi.org/10.31989/ffs.v2i2.885

\begin{abstract}
The gut microbiome incorporates the ecological niche specific to the totality of the microorganisms in the human gut. Unique to every individual, the blueprint of the microbiome sets up at birth and functions as a human organ and plays a significant role in digestion, detoxification, fighting pathogens, modulating the immune system, and improving health. The gut microbiota and associated health implications are influenced by factors such as birth and age, diseases, use of

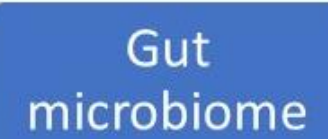

Health modulation

\section{Health}

antibiotics and food components (e.g., complex carbohydrates and dietary fibers, plant proteins, unsaturated fatty acids, and functional compounds of natural origin such as flavones, flavonoids, polyphenols, and antioxidants). Toward this end, diet and the gut microbiome interact and govern each other's fate. Herein, gut dysbiosis, the alteration of natural state and composition of the gut microbiome, and the gut microflora diversity modulated by food constituents and associated health effects have been discussed. The gut microbiota composition and related metabolites are influenced by the diet which in turn modulates human health. The outcome is deemed to aid in developing personalized diet recommendations (based on the unique gut microbiome) toward improving human health.
\end{abstract}

Keywords: gut microbiome, gut microbiota, gut dysbiosis, short-chain fatty acids, metabolites, health modulation

(CFFC 2022. This is an Open Access article distributed under the terms of the Creative Commons Attribution 4.0 License (http://creativecommons.org/licenses/by/4.0) 


\section{INTRODUCTION}

The gut microbiota and its implications on human health have emerged as a critical area in health science. The intrinsic associations between food, microbiotaassociated gut health and overall health are a topic of concern. This paper reviews some important aspects of these three aspects with brevity.

Gut Microbiome: The literature explains the gut microbiome from two different perspectives. One concept incorporates the ideology of the collective genome (pertaining to the suffix -ome that comes from the word -genome) of the micro-organisms residing in the human gut. The other one, however, incorporates the totality of all the micro-organisms, their habitat (the gut; pertaining to the suffix -biome) with unique physiochemical properties, and all their activities inside the habitat thereby forming a unique ecological niche specific to the totality of the micro-organisms residing the habitat. Thus, the gut microbiome could be defined as (1) the collective genome of the microorganisms (bacteria, archaea, lower and higher eukaryotes and viruses) residing in the human gut [1] or (2) the total microorganisms, their habitat (the gut or gastrointestinal canal) and activities [2-3]. The appropriateness of these two perspectives is still a matter of debate but the second one appears to be more apt as it comprehensively signifies the ecological niche. The microbiome (1) is as complex as a human organ, (2) transfers to newborns and (3) shows distinct physiology and pathology [4-6]. Quoting Riccio and Rossano "it could be considered as a kind of sensor of the variations in ... relationship with environmental energy, which mainly occurs through the intake of food and the elimination of waste" [7]. It acts as the interface between the energy obtained from food and energy needs. The microbially derived metabolites also induce epigenetic alterations in the genes responsible for disease modulation [8].

Gut microbiota: The human body harbors trillions of microorganisms and most of them reside in the gut [910]. The gut also accommodates a sparse amount of pathogenic strains ( $0.1 \%$ ) of Escherichia coli, Bacteroides fragilis, Campylobacter jejuni, Salmonella enterica, Vibrio cholera, etc. All the microorganisms that are part of the stable gut microecological niche are categorized as the "gut microbiota", which is the subset of the gut microbiome [11-12]. It comprises around 99.1\% bacteria (e.g., Firmicutes, Bacteroidetes, Actinobacteria and Proteobacteria), 0.8\% archaea (e.g., methanogens and haloarchaeal strains), and $0.1 \%$ of virus (e.g., bacteriophages), fungi (e.g., Ascomycota, Basidiomycota and Zygomycota) and protozoa (e.g., amoebozoans, flagellates, Amitochondriates, Apicomplexans and Stramenophiles) (Table 1).

How does gut microbiota establish and form a stable niche in the human body?: The gut is exposed to the outer environment through air, food and water. The first batch of the human gut microbiota (mainly bacteria) enter during and immediately after birth and colonize within days. The microorganisms such as Lactobacillus spp., Prevotella spp. and Sneathia spp. derived from the mother's vagina during natural delivery or Staphylococcus, Corynebacterium and Propionibacterium spp. from the mother's skin via C-section [22] dictate the overall gut microbial cohort, which later forms the microecosystem within a couple of years. The gut microbiota could also colonize the unborn's gut in the uterus [23]. These prelusive bacteria develop based on nutrition availability (e.g., Human Milk Oligosaccharides) and lay the foundation for the futuristic microbial profile. 
Table 1. Key microorganisms of human gut

\begin{tabular}{|c|c|c|c|}
\hline Organism & Major Phyla & Key members & References \\
\hline \multirow[t]{4}{*}{ Bacteria } & Firmicutes & $\begin{array}{l}\text { Clostridia Cluster XIVa [Clostridium spp., Eubacterium spp., } \\
\text { Roseburia spp. Blautia spp.] and Clostridia Cluster IV } \\
\text { [Clostridium spp., Ruminococcus spp., Faecalibacterium spp.] }\end{array}$ & [12-17] \\
\hline & Bacteroidetes & Bacteroides spp., Prevotella spp., Xylanibacter spp. & \\
\hline & Actinobacteria & Bifidobacterium spp., Propionibacterium spp. & \\
\hline & Proteobacteria & Escherichia coli & \\
\hline \multirow[t]{2}{*}{ Archaea } & Methanogens & $\begin{array}{l}\text { Methanobrevibacter, Methanobacteriales, } \\
\text { Methanomassiliicoccales. }\end{array}$ & [18] \\
\hline & Haloarchaeal strains & Haloferax miserliness and Halorubrum lipolyticum & \\
\hline Virus & Bacteriophages & - & [19] \\
\hline \multirow[t]{3}{*}{ Fungi } & Ascomycota & Candida spp., Cladosporium spp., Saccharomyces spp. & {$[20]$} \\
\hline & Basidiomycota & Cryptococcus spp., Filobasidium spp., Malassezzia spp. & \\
\hline & Zygomycota & - & \\
\hline Protozoa & $\begin{array}{l}\text { Amoebozoans } \\
\text { Flagellates } \\
\text { Amitochondriates } \\
\text { Ciliates } \\
\text { Apicomplexans } \\
\text { Stramenophiles }\end{array}$ & - & [21] \\
\hline
\end{tabular}

Why is the gut microbiota a topic of significance? The gut microbiota plays several vital roles in the human body. For example, Lactobacillus helveticus and Bifidobacterium longum alleviate anxiety and improve psychological health [24]. Herein, gut microbiota effects on (1) the immune system, (2) digestion and nutrition, (3) the integrity of the gut barrier and gastrointestinal tract, (4) detoxification and (5) antimicrobial protection have been discussed in brief.

Immune system: The immune system is a composite of innate and adaptive immune systems. The innate immune system comprises monocytes, macrophages, neutrophils, basophils, eosinophils, mast cells, interleukin-10 (IL-10, an anti-inflammatory signaling protein), natural killer (NK) cells, gut-associated lymphoid tissues (GALT) along with complement and dendritic cells. On the other hand, the adaptive immune system is predominantly composed of dendritic cells and B-cells (fight against bacteria and viruses), and effector and regulatory T-cells (stimulate $\mathrm{B}$-cells to make antibodies e.g., immunoglobulin $A$ and also eradicate invaders). The gut microbiota works in close synergism with these two systems. It aids GALT in recognizing bacterial tolerance and regulating the activation of NK cells and the functionality of T-cells and B-cells [25]. It also contributes to the diversification of microbe recognition capacity of IL-10 and modulates the human immune system [26]. The gut bacteria also facilitates predicting white blood cell counts, neutrophils, lymphocytes, monocytes, eosinophils and platelets [27]. Disbalance in the gut microbial composition encourages monocyte-like macrophages (MLM) accumulation and facilitates tumorigenesis preventing apoptosis and increasing cell survival instincts [28]. 
Digestion and Nutrition: Gut microbiota ferments carbohydrates that survive digestion and reach the colon and releases beneficial metabolites predominantly composed of short-chain fatty acids (SCFAs, e.g., butyrate, acetate, and propionate). The SCFAs (mainly butyrate) become an energy source for the host epithelial cells. The SCFAs also avert the accumulation of metabolic byproducts such as D-lactate and in turn prevent neurological disorders like delirium, ataxia, and slurred speech, to name a few. Examples of the colonic bacteria involved in the fermentation are Bacteroides, Roseburia, Bifidobacterium spp., Fecalibacterium spp., Enterobacteria spp. And the bacteria from Lachnospiraceae family [29]. Similarly, Oxalobacter, Lactobacillus spp. And Bifidobacterium spp. Process oxalate and prevent stone formation in the kidneys [30].

Gut microbiota positively influences lipid

metabolism (mainly in the small intestine) and promotes the Lipoprotein Lipase (LPL) activity that aid in breaking triglycerides into fat molecules used as energy or stored in adipocytes [31]. It also regulates the colipase enzyme expression and facilitates the pancreatic lipase in lipid digestion [32]. It further deconjugates and dehydrates the primary bile acids into secondary bile acids that support fat emulsification and absorption [33]. For example, Lactobacillus curvatus and Lactobacillus plantarum digest and curb cholesterol build-up in the body [34].

Gut microbiota releases bacterial proteinases (small intestine) that act synergistically with intestinal proteases toward modulating protein digestion [35]. Furthermore, it converts amino acids into signaling molecules and antimicrobial peptides (bacteriocins) [36]. Some microbes, e.g., Bifidobacterium, Clostridium, Lactobacillus, Escherichia and Klebsiella act as amine producers too [37]. Likewise, gut microbiota (e.g., Faecalibacterium and Bifidobacterium) also metabolizes polyphenols and activates glycosylated polyphenols by hydrolyzing carbohydrate moieties [38]. Synthesis of vitamin $\mathrm{K}$, components of vitamin $\mathrm{B}$ and conjugated linoleic acid (CLA) are other important attributes [29].

\section{Integrity of the Gut barrier and Gastrointestinal Tract:}

Gut microbiota maintains the gut barrier integrity as well as structural and functional aspects of the gastrointestinal tract. It helps to minimize stress-induced gastrointestinal damage via induction of the epithelial heat-shock proteins (in vivo study), restoration of the tight junction protein structure (human colonic epithelial cell line study), up-regulation of the mucin genes, secretion of defensins (mice study), regulation of NFxB signaling pathway and competitive inhibition of pathogens, to name a few. For example, through mucin synthesis, TJ reassembly, or 25ccluding and ZO-1 upregulation (mice study), the butyrate produced by the gut bacteria improves gut barrier permeability (human colonic epithelial cell line study) [38], Lactobacillus rhamnosus prevents cytokine-induced apoptosis of the intestinal cells (intestinal epithelial cell model) [39] and Akkermansia muciniphila helps to increment the endocannabinoids that can decrease the metabolic endotoxemia and control the gut barrier functions (mice study) [40]. Similarly, gut microbiota maintains tight junctions between cells through TLR2 mediated signaling (mice study) [41]. It also induces the transcription factor angiogenin-3 which is essential during microvasculature development in the intestine. The absence of microvasculature developed lowers the intestinal surface area, the thickness of the intestinal villi, curtails the peristalsis, increases the cell-cycle time and in turn impairs nutrient digestion and absorption [42]. The disbalance in the gut microbiome also leads to a situation called leaky gut where the disrupted gut barrier allows the translocation of the bacteria to the liver through the gut-liver axis that plays role in liver disease development and progression. 
Detoxification: Metals in the elemental, inorganic and/or organic form of ingested food undergo absorption, distribution, biotransformation and elimination. Organic forms readily absorb due to their fat solubility and better membrane diffusivity. However, heavy metals (e.g., lead, arsenic, and cadmium) cause metal toxicity but gut microbiota mitigates metal toxification through biotransformation. For example, Lactobacillus aids in intestinal lead sequestration [43] and Faecalibacterium protects against acute arsenic toxicity [44]. Gut microbiota also absorbs and utilizes metals for its own needs. For example, Bacteroides, Butyricimonas, Dorea and Lactobacillus could consume arsenic, Coprococcus and Lactobacillus cadmium and lead by Desulfovibrio, Prevotella and Roseburia [45].

Antimicrobial Protection: Healthy gut microbiota is essential for normal homeostasis. It creates, however, a challenging scenario for the gut epithelial linings to accept commensal microbiota and reject harmful ones (e.g., through nutrition competition, variation in the oxidative stress, redox potential, and production of bacteriocins). Unlike the large intestine, wherein the twolayered mucus membrane prevents microbial access to the gut epithelial cells, the small intestine, possessing discontinuous and inadequate mucus layer, precludes harmful microbial invasion with its antimicrobial proteins (AMPs) and gut microbiota assistance [46-47]. The gut microbiota induces the Paneth cells to synthesize AMPs such as cathelicidins, C-type lectins, and (pro)defensins through the pattern recognition receptor (PRR) mediated mechanism. The PRR gets activated by organism-specific microbe-associated molecular patterns (MAMPs). Interactions between PRR and MAMPs trigger signaling pathways that promote the production of AMPs, mucin glycoproteins and Immunoglobin A $(\operatorname{IgA})$, which in turn enhance the mucosal barrier functionality [48]. The AMPs production is driven by healthy gut microbiota, and bacteria such as Bacteroides theataiotaomicron and Lactobacillus innocua are essential in this process. The SCFAs produced by the microbiota also induce the AMPs fabrication.

Gut microbiota also stimulates local immunoglobulins production. Gram-negative bacteria such as Bacteroides help to activate the intestinal dendritic cells (DCs), which in turn fuels plasma cells to produce secretory $\lg A(\operatorname{sg} A)$. The $\operatorname{sg} A$ coats the gut microbiota and resists degradation by by the mesenteric lymph nodes, ensuring that the bacterial proteases [49]. Moreover, DCs loaded with gut microbiota are restricted to the mucosal layers systemic immune system remains unaffected by the immune responses around the gut microbiota [50].

Gut Dysbiosis: Every human body has a unique stable gut microbiome (which varies over time due to various factors discussed later), and the relative proportion of specific taxonomic groups vary greatly. Once the stable gut microbiota establishes, the core composition shapes futuristic bacteria in conjunction with factors such as food and prevalent diseases. However, any substantial alteration leads to gut disbalance known as gut dysbiosis resulting in health aberrations such as obesity, cardiovascular diseases, hypertension, diabetes, and inflammatory bowel disease. On the other hand, the increment of certain bacteria is good for cardiovascular health. For example, domination from some bacteria from Firmicutes phylum such as Lactobacillus reuteri is linked with increased High-density Lipoproteins is good for health [51], and Akkermansia muciniphila and Phascolarctobacterium have been linked to fat deposition [52]. Likewise, increased Bacteroides fragilis, Fusobacterium nucleatum, Porphyromonas asaccharolytica, Parvimonas micra, Prevotella 
intermedia, Alistipes finegoldii and Thermanaerovibrio acidaminovorans have been linked to colorectal cancer [53]. Similarly, reduced Faecalibacterium prausnitzii, Erysipelotrichales, Bacteroidales and Clostridiales link to Corhn's disease [54]. Decreased Bifidobacterium and increased Bacteroides and Enterococci might hint the Inflammatory Bowel Disease (IBD) [55]. The gut microbiota also plays roles in the gut-brain axis in a bi- directional fashion through neural, endocrine, immune and humoral pathways. For example, alteration of healthy gut bacteria profile has been linked with central nervous disorders such as autism and depressive behaviors and gut-related issues such as IBD. Gut dysbiosis associated with a couple of health implications is highlighted in Table 2.

Table 2. Decrement in some gut bacteria proportion during diseases

\begin{tabular}{|c|c|c|}
\hline Disease & Gut bacteria & References \\
\hline Autism & $\begin{array}{l}\text { Firmicutes } \\
\text { Actinobacteria }\end{array}$ & {$[21,56,57]$} \\
\hline Celiac Disease & Bifidobacterium & {$[21]$} \\
\hline Clostridium difficile infection & Clostridium scindens & \\
\hline Colorectal cancer & $\begin{array}{l}\text { Prevotella } \\
\text { Ruminococcus spp. } \\
\text { Pseudobutyrivibrio ruminis }\end{array}$ & {$[21,56,58]$} \\
\hline Crohn's disease & $\begin{array}{l}\text { Bacteroides } \\
\text { Bifidobacteria }\end{array}$ & {$[21,56,59]$} \\
\hline Depression & Prevotella, Dialister & \\
\hline HIV & $\begin{array}{l}\text { Clostridia } \\
\text { Bacteroidia } \\
\text { Lactobacilli } \\
\text { Bifidobacteria }\end{array}$ & {$[21,56,60-62]$} \\
\hline Hypertension & Acetate and butyrate producers & [21] \\
\hline Irritable bowel syndrome & Clostridium laptum, Bifidobacteria & [21] \\
\hline Obesity & Bacteroides & {$[21,56,63]$} \\
\hline Rheumatic arthritis & $\begin{array}{l}\text { Bifidobacteria } \\
\text { Bacteroides fragilis }\end{array}$ & {$[21,56,64]$} \\
\hline Type-1 diabetes & $\begin{array}{l}\text { Lactobacillus } \\
\text { Bifidobacterium } \\
\text { Blautia coccoides } \\
\text { Eubacterium rectale } \\
\text { Prevotella } \\
\text { Actinobacteria } \\
\text { Firmicutes }\end{array}$ & {$[21,56,65]$} \\
\hline Type- 2 diabetes & $\begin{array}{l}\text { Clostridium coccoides } \\
\text { Firmicutes, Prevotella, Atopobium }\end{array}$ & {$[21,56,66]$} \\
\hline Ulcerative colitis & $\begin{array}{l}\text { Lactobacilli } \\
\text { Runinococcus hominis } \\
\text { Faecalibacterium prausnitzii }\end{array}$ & {$[21,67-69,56]$} \\
\hline
\end{tabular}


Factors affecting the gut microbiome: Genetics, food, age, diseases and the use of medicines and antibiotics are some of the influencing factors that modulate the gut microbiota cohort throughout human life. A few of them are selected for further elaboration in the following sections.

\section{Host interior factors}

Birth and Age: The first meconium loaded with a few gut microbiota species suggests that the blueprint of the gut microbiome on sets at birth. Indeed, the mode of delivery lays the foundation for the futuristic microbiota composition. The initial inoculum, however, is not necessarily stable and diverse, but manifests into established composite by 3 years and resembles $40-60 \%$ of the adult microbiota profile; however, varies significantly with age [70]. It reaches a stable state at around 30 years but continues to stabilize up to 70 years [71] and is predominantly influenced by environmental exposure, diet, life events, contraction of diseases and consumption of antibiotics. Human milk oligosaccharides (HMOs) consumed during lactation might not necessarily be present in the adult diet. Therefore, infants have an abundant presence of certain Bifidobacterium species such as Bifidobacterium breve, Bifidobacterium bifidum, Bifidobacterium longum subsp. longum (Bifidobacterium longum), Bifidobacterium longum subsp. infantis (Bifidobacterium infantis), Bifidobacterium pseudocatenulatum etc. compared to adults [72]. The Bacteroides and Bifidobacterium in young children and adolescents differ significantly from adults. The E. coli, Proteobacteria and Staphylococcus proliferate with age, whilst Bifidobacteria, Firmicutes and Faecalibacterium prausnitzii decline [73]. Such dynamics negate an individual's ability to synthesize vitamin B12, increase the host's tendency for DNA alterations and weaken the immune system in addition to a host of other health anomalies [74].

\section{Non-dietary factors}

Antibiotics: Gut microbiota contains a pool of genes that express antibiotic resistance. However, upon antibiotics administration, bacterial species with resistant genes competitively flourish over non-resistant bacteria resulting in altered microbial diversity and instability in the overall gut microbiota profile. Such resistant genes can also be transferred to the pathogenic strains. This phenomenon further compromises microbial recognition capacity of the immune system leading to several health issues. It further modifies the metabolome (collection of metabolites), increases antibiotic resistance, and impairs the competitive inhibitory effect on the external pathogens. The mechanisms by which the antibiotic affects the gut bacteria include inhibition of cell wall synthesis, protein synthesis, nucleic acid synthesis, membrane disruption, etc. In this regard, different antibiotics act distinctly. For example, meropenem, gentamicin, and vancomycin administration reduces the Bifidobacterium and butyrate-producing species and promotes Enterobacteriaceae. Likewise, Vancomycin/imipenem diminishes Lachnospiraceae and Ruminococcaceae bacteria that are responsible for the conversion of arabinitol to pentose sugars [75].

Dietary factors: Interactions between gut microbiota and diet significantly influence the metabolic response to nutrition and in turn human health. In general, fruits, vegetables, fibers, and whole plant-based foods promote 
the richness and diversity of gut microbiota compared to animal-based and/or processed foods [76] and aid in the prevention of chronic non-communicable diseases including cancer. Modulating human health through personalized diet recommendations for individuals (with their unique gut microbiome) is deemed to emerge as a new area of diet therapy. Herein, interactions between food classes and gut microbiota, and resultant health effects are highlighted.

Carbohydrates: Gut microbiota interacts with (1) dietary fibers, (2) digestible but undigested carbohydrates by the gut from diet and (3) endogenousglycans from the mucus of the host. In this set, dietary fibers are the major energy source for the gut microbiota, known as microbiota accessible carbohydrates (MACs), for brevity. The fibrinolytic (fiber digesting) community includes Roseburia, Ruminococcus, Bacteroides and Bifidobacterium, etc. Likewise, the glycolytic (that digest the gut-digestible carbohydrates, but somehow skip the digestion in the gut) cohort includes Lactobacillus, Enterococcus, Staphylococcus, E. coli, etc. These microbes ferment complex fibers, sugars, and endogenous carbohydrates resulting in SCFAs (acetate, propionate, butyrate), carboxylic acids (e.g., lactate, succinate, and formate) along with various gases namely $\mathrm{CO}_{2}, \mathrm{H}_{2}, \mathrm{H}_{2} \mathrm{~S}$ and $\mathrm{CH}_{4}$, which could further get interconverted. SCFAs are the energy source for the intestinal epithelial cells (colonocytes). Butyrate in particular will be utilized by colonocytes, whereas acetate and propionate in the gluconeogenesis process by the liver as well as transported through the bloodstream to the brain and heart [77]. Consequently, reduction in fiber consumption impacts SCFAs products that concomitantly influence the gut microbial diversity that further resulting in a host of health issues.

Among the several available MACs (Table 3), resistant starch (RS) increases Lactobacilli, Bifidobacteria, Roseburia, Eubacteria and Ruminococcus species; RS2 Ruminococcus bromii and Eubacterium rectale, RS3 Faecalibacterium prausnitzii and RS4 Bifidobacterium adolescentis and Parabacteroides distasonis [78]. Pectin boosts the relative abundance of Bacteroides, Anaeroplasma, Anaerostipes and Roseburia, but decreases Alistipes and Bacteroide. Likewise, cellulose promotes Clostridium, Eubacterium, Ruminococcus, Bacteroides, etc., whilst Inulin upsurges E. rectale, Roseburia intestinalis and Anaerostipes caccae and xanthan gum fosters Roseburia, Ruminococcus, Bacteroides and Bifidobacterium with an increase in the overall SCFAs production along with resistance against diarrhea-causing Clostridioides difficile [79]. Similarly, arabinoxylans rise the butyrate-producing species such as Bifidobacterium [80] and xylan fermenting species such as Bacteroidetes [81]. Diets with low MACs promote mucus degrading bacteria e.g., Akkermansia muciniphila and Bacteroides caccae, that impair the first line of defense in the human gut leading to gut dysbiosis [82], decreased epithelial integrity and modification of epithelium cytokine expression [83-84]. Diets rich in glucose, fructose, sucrose, and lactose promote Bifidobacteria and decrease Bacteroides [85-86]. Likewise, lactose blooms Lactobacilli but tapers Clostridia. Artificial sweeteners (e.g., saccharin, aspartame) decrease Lactobacilli and Clostridia [87]. 
Table 3. A few carbohydrates and artificial sweetener fermented by some gut microbiota

\begin{tabular}{|c|c|c|}
\hline $\begin{array}{l}\text { Fermenting } \\
\text { organism }\end{array}$ & & rences \\
\hline Bacteroides uniformis & Agarose & [13] \\
\hline $\begin{array}{l}\text { Bifidobacteria, Bacteroides xylanisolvens, Bacteroides } \\
\text { thetaiotaomicron, Bacteroides ovatus }\end{array}$ & Alginate & {$[15,88]$} \\
\hline Bifidobacterium, Anaerostipes, Prevotella & Bacterial polysaccharides & [13] \\
\hline Bifidobacterium, Lactobacillus, Bacteroides & Beta-glycan & {$[88]$} \\
\hline Bacteroides xylanisolvens, Escherichia coli & Carrageenan & [89] \\
\hline Ruminococcus, Bacteroides & Cellulose & [13] \\
\hline $\begin{array}{l}\text { Bacteroides, Roseburia, Faecalibacterium, } \\
\text { Bifidobacterium }\end{array}$ & Fructans (inulin and FOS) & [13] \\
\hline Bifidobacterium, Lactobacillus, Bacteroides & Fructooligosaccharide & [88] \\
\hline Bifidoacterium, Roseburia & Fructose & [13] \\
\hline Akkermansia & Fucoidan & {$[88]$} \\
\hline Bifidobacterium & Galacto oligosaccharide & {$[88]$} \\
\hline Bifidobacterium, Roseburia, Eubacterium rectale & Guar gum & {$[88]$} \\
\hline Bifidobacterium, Lactobacillus & Gum acacia & {$[88]$} \\
\hline Clostridial cluster XIVa, Bifidobacterium & Hemicellulose & {$[88]$} \\
\hline Lactobacillus. Bifidobacterium & Lactose & [13] \\
\hline Bifidobacterium & Milk oligosaccharides & [13] \\
\hline Akkermansia, Bacteroides & Mucin and mucopolysaccharides & [13] \\
\hline Peptostreptococcus, Fusobacterium, Bifidobacterium & Nutriose & {$[90]$} \\
\hline Bacteroides, faecalibacterium & Pectin & [13] \\
\hline $\begin{array}{l}\text { Eubacterium rectale, Bacteroidetes, Ruminococcus } \\
\text { bromii, Bifidobacterium, Akkermansia, Allobaculum }\end{array}$ & Resistant starch II & {$[88]$} \\
\hline $\begin{array}{l}\text { Eubacterium rectale, Ruminococcus bromii, } \\
\text { Oscillibacter, Atopobium spp., Bifidobacteria spp. }\end{array}$ & Resistant starch III & {$[88]$} \\
\hline $\begin{array}{l}\text { Eubacterium oxidoreducens, Ruminococcus lactaris, } \\
\text { Parabacteroides distasonis, Eubacterium rectale, } \\
\text { Rumminococcus bromii }\end{array}$ & Resistant starch IV & {$[88]$} \\
\hline Bacteroidetes & Saccharin (artificial sweetner) & [91] \\
\hline Lactobacillus, Escherichia & Sugar-alcohols & [13] \\
\hline Roseburia, Bacteroides, Prevotella & Xylan and arabinoxylan & [13] \\
\hline
\end{tabular}

Proteins: Microbial proteinases digest proteins, in association with proteinases and peptidases, and aid in protein metabolism. The gut microbiota also converts amino acids to signaling molecules and antimicrobial 
peptides [92]. The presence, absence, or type of protein in conjunction with the levels of oxygen and carbohydrate significantly affect the gut microbial profile. For example, animal proteins increase Alistipes, Bilophila and Clostridia along with subtle increment in Eubacterium rectale and Bifidobacteria, which could promote bile-tolerant anaerobes and subsequent reduction of SCFAs along with increment in the production of Trimethylamine $\mathrm{N}$-oxide (TMAO) thereby increasing the risks of cardiovascular diseases and Inflammatory Bowel Diseases [93]. On the other hand, the consumption of plant-based proteins appears to be favorable [94]. Whey protein discourages the growth of Bacteroides and Clostridia but increases Bifidobacteria and Lactobacilli [95]. The Bifidobacterium, Lactobacillus increment with concomitant Bacteroides and Clostridium spp. Reduction augments SCFAs production, which reduces inflammation and improves gut barrier and production of Tregs regulatory cells [96].

Fats: Gut microbiota positively impacts lipid metabolism by promoting Lipoprotein Lipase (LPL) activity and colipase expression [97]. However, fat type and amount influence the microbial cohort. Consumption of lower amounts of fat increases the Bifidobacterium spp. while higher quantities proliferate anaerobic microbes and Bacteroides [98]. Likewise, diets rich in saturated fats enhance Faecalibacterium prausnitzii. On the other hand, monounsaturated fats aid to reduce the overall bacterial load. Lard promotes Bacteroides and Bilophila growth whilst Bifidobacteria, Adlercreitzia, Lactobacillus, Streptococcus and Akkermansia muciniphila by fish-oil [99]. Mice studies hint at increased systemic TLR stimulation, inflammation of the adipose tissues and decreased insulin sensitivity compared to fish-oil consumption suggesting some relationship between developed gut microbiota and health issues [96].
However, further research is warranted to understand the root cause.

Natural compounds: A variety of natural food systems such as vegetables, fruits and herbs contain healthpromoting and disease-preventing compounds (e.g., catechins, flavonols, flavones, anthocyanins, proanthocyanidins, phenolic acids and polyphenols) and gut microbiota plays important role in metabolizing these compounds. Gut microbiota transforms these natural compounds to a more active and absorbable form via esterase, glucosidase, demethylation, dehydroxylation and decarboxylation [100]. For example, polyphenols that are naturally present as glycosides are transformed to aglycones by the gut microbiota glycohydrolases, which are better absorbed in the intestine. Gut microbiota is also essential to produce active isoflavone metabolites with oestrogen-like activity that display various anti-inflammatory properties. For example, quercetin derived through microbial digestion possesses improves anti-inflammatory properties than the glycosylated form [101].

The presence or absence of these beneficial compounds modulates the gut microbial composition. Flavonol-rich foods promote healthy gut bacteria [102]. Polyphenols from tea, wine and cocoa prosper the Bifidobacteria and Lactobacillus species with a concomitant reduction in the pathogenic strains such as Staphylococcus aureus, Salmonella typhimurium, Clostridium perfringens, Clostridium Histolyticum, Bacteroides, Salmonella typhimurium and Staphylococcus aureus [103]. Tea phenolics reduce Bacteroides spp., Clostridium spp., E. coli and Salmonella typhimurium [104]. Wine resveratrol promotes the growth of Bifidobacterium and Lactobacillus [105]. Anthocyanins from berries inhibit pathogens such as Staphylococcus, Salmonella spp., Helicobacter pylori and Bacillus cereus [106]. Tea catechins modify the intestine 
mucin layer toward modulating adhesion and colonization of the bacteria in the gut [107].

\section{CONCLUSION}

The gut microbiome, the ecological niche formed by the gut microbiota, is influenced by factors such as birth, age, antibiotics, diseases, food, etc. It interacts with the outer environment through food, water, and air. More importantly, food and water are the major influencing factors through which the gut microbiome could get modified and in turn modulate human health. For example, consumption of an animal-protein-rich diet appears to reduce Roseburia and Eubacterium rectale which are associated with increased risks of IBD. On the other hand, the presence of MACs increases Lactobacillus, Ruminococcus, Eubacterium rectale and Roseburia and the overall SCFA production. Probiotics and polyphenols favor beneficial Bifidobacterium and lactic acid bacteria and reduce the enteropathogenic Clostridia species. The metabolites formed during this process also play critical roles in antimicrobial protection and immunomodulation. This brief review provides a synopsis of the gut microbiota and its interplay with diet and health. Diet-induced health modulation could hold a promising future via the pathway of inter-dependent micro-ecosystem of food, gut microbiome and human health toward improving human health.

List of Abbreviations: IBD: inflammatory bowel diseases, MAC: microbiota accessible carbohydrates, SCFA: shortchain fatty acids, LPL: lipoprotein lipase, TMAO: Trimethylamine N-oxide, RS: resistant starch, HMO: human milk oligosaccharides, DNA: deoxyribonucleic acid, DC: dendritic cells, AMP: antimicrobial proteins, MAMP: microbe-associated-molecular patterns, NFxB: nuclear factor kappa-light-chain-enhancer of activated $B$ cells, CLA: conjugated linoleic acid, MLM: monocyte-like macrophages, IL: interleukin, NK: natural killer, GALT: gut-associated lymphoid tissue

Authors Contribution: SB: Conceptualization, Investigation, Data curation, Resources, Writing - original draft; SJ: Project administration, Funding acquisition, Supervision, Writing - review and editing

Competing Interests: We declare no competing interests.

Acknowledgment/Funding: Support is from the USDA National Institute for Food and Agriculture (SD0OH64818). We thank Dr. Sanjeev Anand for his critique of the draft.

\section{REFERENCES}

1. Lederberg J, Mccray AT: Ome sweet `omics--a genealogical treasury of words. Scientist 2001,15:8.

2. Whipps JM, Lewis K, Cooke RC: Mycoparasitism and plant disease control. In: Fungi in Biological Control Systems. Edited by Burge, NM: Manchester University Press; 1988: 161-187.

3. Berg G, Rybakova D, Fischer D, Cernava T, Vergès M-CC, Charles T, Chen X, Cocolin L, Eversole K, Corral GH, Kazou M, Kinkel L, Lange L, Lima N, Loy A, Macklin JA, Maguin E, Mauchline T, Mcclure R, Mitter B, Ryan M, Sarand I, Smidt H, Schelkle B, Roume H, Kiran GS, Selvin J, Souza RSCD, Van Overbeek L, Singh BK, Wagner M, Walsh A, Sessitsch A, Schloter M: Microbiome definition re-visited: old concepts and new challenges. Microbiome 2020, 8. https://doi.org/10.1186/s40168-020-00875-0

4. O'Hara AM, Shanahan F: The gut flora as a forgotten organ. EMBO Rep. 2006, 7:688-693. https://doi.org/10.1038/sj.embor.7400731

5. Baquero F, Nombela C: The microbiome as a human organ. Clin Microbiol Infect 2012, 18 (Suppl 4):2-4. https://doi.org/10.1111/j.1469-0691.2012.03916.x 1

6. Clarke G, Stilling RM, Kennedy PJ, Stanton C, Cryan JF, Dinan TG, Pharmabiotic Centre A: Minireview: gut microbiota: the neglected endocrine organ. Mol Endocrinol 2014, 28:12211238. https://doi.org/10.1210/me.2014-1108 
7. Riccio $P$, and Rossano $R$ : The human gut microbiota is neither an organ nor a commensal. FEBS Lett 2020, 594:20. https://doi.org/10.1002/1873-3468.13946

8. 8.Yuille S, Reichardt N, Panda S, Dunbar H, and Mulder IE: Human gut bacteria as potent class I histone deacetylase inhibitors in vitro through production of butyric acid and valeric acid. Plos One 2018, 13:7.

https://doi.org/10.1371/journal.pone.0201073

9. $\mathrm{NIH}$, Human Microbiome Project defines normal bacterial makeup of the body, 2012 [https://www.nih.gov/newsevents/news-releases/nih-human-microbiome-project-

defines-normal-bacterial-makeup-body] Retrieved Dec 24, 2021

10. Sender R, Fuchs S, Milo R: Revised estimates for the number of human and bacteria cells in the body. Plos Biol, 201614. https://doi.org/10.1371/journal.pbio.1002533

11. Pickard JM, Zeng MY, Caruso R, Núñez G: Gut microbiota: role in pathogen colonization, immune responses, and inflammatory disease. Immunol Rev 2017, 279: 70-89. https://doi.org/10.1111/imr.12567

12. Cresci GAM, Izzo K: Gut microbiome, Adult short bowel syndrome: nutritional, medical, and surgical management. Ed. 1, Edited by Corrigan M, Roberts K, Steiger E. USA: Academic Press. https://www.elsevier.com/books/adultshort-bowel-syndrome/corrigan/978-0-12-814330-8

13. Chassard C, Lacroix C: Carbohydrates and the human gut microbiota. Curr Opin Clin Nutr Metab Care 2013, 16: 453460. https://Doi.org10.1097/MCO.0b013e3283619e63

14. Belizário JE, Faintuch J, Garay-Malpartida M: Gut microbiome dysbiosis and immunometabolism: new frontiers for treatment of metabolic diseases. Mediat. Inflamm 2018, 1-12.

https://doi.org/10.1155/2018/2037838

15. Li M, Li G, Shang Q, Chen X, Liu W, Pi X, Zhu L, Yin Y, Yu G, Wang, $X$ : In vitro fermentation of alginate and its derivatives by human gut microbiota. Anaerobe 2016, 39:19-25. https://doi.org/10.1016/j.anaerobe.2016.02.00

16. Hehemann JH, Kelly AG, Pudlo NA, Martens EC, Boraston AB: Bacteria of the human gut microbiome catabolize red seaweed glycans with carbohydrate-active enzyme updates from extrinsic microbes. Proc Natl Acad Sci 2012, 109:1978691. https://doi.org/10.1073/pnas.1211002109

17. Kho ZY, Lal SK: The human gut microbiome - a potential controller of wellness and disease. Front Microbiol 2018, 9. https://doi.org/10.3389/fmicb.2018.01835
18. Kim JY, Whon TW, Lim MY, Kin YB, Kwon MS, Kin J, Lee SH, Choi HJ, Nam IH, Chung WH, Kin JH, Bae JW, Roh SW, Nam YD: The human gut archaeome: identification of diverse haloarchaea in Korean subjects. Microbiome 2020, 8:114. https://doi.org/10.1186/s40168-020-00894-x

19. Lecuit M, Eloit M: The viruses of the gut microbiota. In The microbiota in gastrointestinal pathophysiology 2017, 179183. https://doi.org/10.1016/b978-0-12-804024-9.00021-5

20. Pérez JC. Fungi of the human gut microbiota: roles and significance. International Journal of Medical Microbiology 2021, 311:151490. https://doi.org/10.1016/j.ijmm.2021.151490

21. Chabé M, Lokmer A, Ségurel L: Gut protozoa: friends or foes of the human gut microbiota?. Trends Parasitol 2017, 33:925-934. https://doi.org/10.1016/j.pt.2017.08.005https://doi.org/10 $.1093 / \mathrm{ajcn} / 69.5 .1035 \mathrm{~s}$

22. Dominguez-Bello MG, Costello EK, Contreras $M$, Magris $M$, Hidalgo G, Fierer N, Knight R: Delivery mode shapes the acquisition and structure of the initial microbiota across multiple body habitats in newborns. Proc. Natl. Acad. Sci. U. S. A. $2010,107: 11971-11975$. https://www.doi.org/10.1073/pnas.1002601107

23. Ardissone AN, Cruz DM, Davis-Richardson AG, Rechcigl KT, Li N, Drew JC, Murgas-Torrazza R, Sharma R, Hudak ML, Triplett EW, Neu J: Meconium microbiome analysis identifies bacteria correlated with premature birth. PLoS One 2014, 9:1-8. https://doi.org/10.1371/journal.pone.0090784

24. Messaoudi M, Lalonde R, Violle N, Javelot H, Desor D, Nejdi A: Assessment of psychotropic-like properties of a probiotic formulation (Lactobacillus helveticus R0052 and Bifidobacterium longum R0175) in rats and human subjects. Br J Nutr 2011, 105:755. https://doi.org/10.1017/S0007114510004319

25. Rhee KJ, Sethupathi P, Driks A, Lanning DK, Knight K: Role of commensal bacteria in development of gut-associated lymphoid tissues and preimmune antibody repertoire. J Immunol 2004, 172:1118-1124.

https://doi.org/10.4049/jimmunol.172.2.1118

26. Singh V, Kumar M, San Yeoh B, Xiao X Saha, P, Kennett MJ, Vijay-Kumar M: Inhibition of interleukin-10 signaling induces microbiota-dependent chronic colitis in apolipoprotein $E$ deficient mice. Inflamm Bowel Dis 2016, 22: 841-852. https://doi.org/10.1097/MIB.0000000000000699 
27. Schluter J, Peled JU, Taylor BP, Markey KA, Smith M, Taur Y, Niehus R, Staffas A, Dai A, Fontana E, Amoretti LA, Wright RJ, Morjaria S, Fenelus M, Pessin MS, Chao NJ, Lew M, Bohannon L, Bush A, Sung AD, Xavier, JB: The gut microbiota is associated with immune cell dynamics in humans. Nature 2020, 588:783720. https://doi.org/doi.org10.1038/s41586$\underline{020-2971-8}$

28. Yang $Y$, Li L, Xu C, Wang Y, Wang Z, Chen M, Jiang Z, Pan J, Yang C, Li X, Song K, Yan J, Xie W, Wu X, Chen Z, Yuan Y, Zheng S, Yan J, Huang J, Qiu F: Cross-talk between the gut microbiota and monocyte-like macrophages mediates an inflammatory response to promote colitis-associated tumourigenesis. Gut 2021, 70:1495.

https://doi.org/10.1136/gutjnl-2020-320777

29. Jandhyala SM, Talukdar R, Subramanyam C, Vuyyuru H, Sasikala M, Reddy N: Role of the normal gut microbiota. World J Gastroenterol 2015, 21:29. https://doi.org/10.3748/wjg.v21.i29.8787

30. Hatch M: Gut microbiota and oxalate homeostasis. Ann Transl Med 2017, 536. https://www. https://doi.org/10.21037/atm.2016.12.70

31. Matey-Hernandez ML, Williams F, Potter T, Valdes AM, Spector TD, Menni C: Genetic and microbiome influence on lipid metabolism and dyslipidemia. Physiol Genomics 2018, 50:117-126. https://doi.org/10.1152/physiolgenomics.00053.2017

32. Hooper LV, Wong MH, Thelin LA, Hansson, Falk PG, Gordon $\mathrm{JI}$ : Molecular analysis of commensal host-microbial relationships in the intestine. Science 2001, 291:881-884. https://doi.org/10.1126/science.291.5505.881

33. Molinero N, Ruiz L, Sánchez B, Margolles A, Delgado S: Intestinal bacteria interplay with bile and cholesterol metabolism: implications on host physiology. Front physiol 2019, 10. https://doi.org/10.3389/fphys.2019.00185

34. Jeun J, Kim S, Cho SY, Jun H, Park HJ, Seo JG: Hypocholesterolemic effects of Lactobacillus plantarum КСТC3928 by increased bile acid excretion in C57BL/6 mice. Nutrition 2010, 26:321-330.

https://doi.org/10.1016/j.nut.2009.04.011

35. Cox LM, Weiner HL: Microbiota signaling pathways that influence neurologic disease neurotherapeutics. Neurotherapeutics 2018,15:135-145. https://doi.org/10.1007/s13311-017-0598-8

36. Pugin B, Barcik W, Westermann P, Heider A, Wawrzyniak M, Hellings $P$, Akdis CA, O'Mahony L: A wide diversity of bacteria from the human gut produces and degrades biogenic amines. Microb Ecol Health Dis 2017, 28. https://doi.org/10.1080/16512235.2017.1353881

37. Stevens JF, Maier CS: The chemistry of gut microbial metabolism of polyphenols. Phytochem Rev 2016, 15:425444. https://doi.org/10.1007/s11101-016-9459-z

38. Allam-Ndoul B, Castonguay-Paradis S, Veilleux A: Gut microbiota and intestinal trans-epithelial permeability. Int J Mol 2020, 21:6402. https://doi.org/10.3390/ijms21176402

39. Hausmann M: How bacteria-induced apoptosis of intestinal epithelial cells contributes to mucosal inflammation?. Int J Inflam 2010, 2010. https://doi.org/10.4061/2010/574568

40. Cani P, Plovier H, Van Hul M: Endocannabinoids - at the crossroads between the gut microbiota and host metabolism. Nat Rev Endocrinol 2016, 12:133-143. https://doi.org/10.1038/nrendo.2015.211

41. Ulluwishewa D, Anderson RC, McNabb WC, Moughan PJ, Wells JM, Roy NC: Regulation of tight junction permeability by intestinal bacteria and dietary components. J. Nutr 2011, 141:769-776. https://doi.org/10.3945/jn.110.135657

42. Sun D, Bai R, Zhou W, Yao Z, Liu Y, Tang S, Ge X, Luo L, Luo C, Hu GF, Sheng J, Xu Z: Angiogenin maintains gut microbe homeostasis by balancing $\alpha$-Proteobacteria and Lachnospiraceae. Gut 2021, 70:666-676. https://doi.org/10.1136/gutjnl-2019-320135

43. Brunton LL, Knollman B, Goodman, Gilman: The pharmacological basis of therapeutics, Ed. 12, 2015, McGraw-Hill.

https://accessmedicine.mhmedical.com/content.aspx?boo $\underline{\text { kid }=1613 \& \text { sectionid }=102124003}$

44. Zhai Q, Liu Y, Wang C, Qu D, Zhao J, Zhang H, Tian F, Chen W: Lactobacillus plantarum CCFM8661 modulates bile acid enterohepatic circulation and increases lead excretion in mice, Food 2019,10:1455-1464. https://doi.org/10.1039/C8F002554A

45. Monroy-Torres R, Hernandez-Luna M, Ramirez-Gomez XS, Lopez-Briones S: Role of the microbiome as the first metal detoxification mechanism. In Prebiotics and Probiotics Potential Benefits in Nutrition and Health. Intech 2019. https://doi.org/10.5772/intechopen.89232

46. Paone P, Cani PD: Mucus barrier, mucins and gut microbiota: the expected slimy partners?. Gut 2020, 69:2232-2243. https://doi.org/10.1136/gutjnl-2020-322260

47. Liu $T$, Liang $X$, Lei $C$, Huang $Q$, Song $W$, Fang R, Li C, Li X, Mo H, Sun N, Lv H, Liu Z: High-fat diet affects heavy metal 
accumulation and toxicity to mice liver and kidney probably via gut microbiota. Front microbiol 2020, 11:1604. https://doi.org/10.3389/fmicb.2020.01604

48. Corthésy B: Multi-faceted functions of secretory IgA at mucosal surfaces. Front immunol 2013, 4:185. https://doi.org/10.3389/fimmu.2013.00185

49. Peterson, DA, McNulty NP, Guruge JL, Gordon, JI: IgA response to symbiotic bacteria as a mediator of gut homeostasis. Cell Host Microbe 2007, 2: 328-339. https://doi.org/10.1016/i.chom.2007.09.013

50. Macpherson AJ, Uhr T: Induction of protective IgA by intestinal dendritic cells carrying commensal bacteria. Science 2004, 12:1662-1665. https://doi.org/10.1126/science.1091334

51. Kazemian, N, Mahmoudi M, Halperin F: Gut microbiota and cardiovascular disease: opportunities and challenges. Microbiome 2020, 8:36. https://doi.org/10.1186/s40168$\underline{020-00821-0}$

52. Davis CD: The Gut Microbiome and Its Role in Obesity. Nutr Today 2016, 51:167-174. https://doi.org/10.1097/NT.0000000000000167

53. Sánchez-Alcoholado L, Ramos-Molina B, Otero A, LabordaIllanes A, Ordóñez R, Medina, JA, Gómez-Millán J, QueipoOrtuño, MI: The role of the gut microbiome in colorectal cancer development and therapy response. Cancers 2020, 12:1406.

https://doi.org/10.3390/cancers12061406

54. Carding S, Verbeke K, Vipond DT, Corfe BM, Owen L: Dysbiosis of the gut microbiota in disease. Microb Ecol Health Dis 2015, 26:26191. https://doi.org/ 10.3402/mehd.v26.26191

55. Zhou Y, Chen H, He H, Du Y, Hu J, Li Y, Li Y, Zhou Y, Wang H, Chen $Y$, Nie $Y$ : Increased Enterococcus faecalis infection is associated with clinically active Crohn disease. Medicine 2016, 95:e5019. https://doi.org/10.1097/MD.0000000000005019

56. Machiels K, Joossens M, Sabino J, De Preter V, Arijs I, Eeckhaut V, Ballet V, Claes K, Van Immerseel F, Verbeke K, Ferrante $M$, Verhaegen J, Rutgeerts $P$, Vermeire S: A decrease of the butyrate-producing species Roseburia hominis and Faecalibacterium prausnitzii defines dysbiosis in patients with ulcerative colitis. Gut 2014, 63:1275-1283. https://doi.org/10.1136/gutjnl-2013-304833

57. Wolf BW, Wheeler KB, Ataya DG, Garleb KA: Safety and tolerance of Lactobacillus reuteri supplementation to a population infected with the human immunodeficiency virus. Food Chem Toxicol 1998, 36:1085-1094. https://doi.org/10.1016/s0278-6915(98)00090-8

58. Larsen N, Vogensen FK, van den Berg FW, Nielsen DS, Andreasen AS, Pedersen BK, AI-Soud WA, Sørensen SJ, Hansen LH, Jakobsen M: Gut microbiota in human adults with type 2 diabetes differs from non-diabetic adults. PLoS One 2010, 5:e9085. https://doi.org/10.1371/journal.pone.0009085

59. Zhang YJ, Li S, Gan RY, Zhou T, Xu DP, Li HB: Impacts of gut bacteria on human health and diseases. Int J Mol Sci 2015, 16:7493-519. https://doi.org/10.3390/ijms16047493

60. Weir TL, Manter DK, Sheflin AM, Barnett BA, Heuberger AL, Ryan EP: Stool microbiome and metabolome differences between colorectal cancer patients and healthy adults. PLoS One 2013, 8:e70803.

https://doi.org/10.1371/journal.pone.0070803

61. Vujkovic-Cvijin I, Dunham RM, Iwai S, Maher MC, Albright RG, Broadhurst MJ, Hernandez RD, Lederman MM, Huang $Y$, Somsouk M, Deeks SG, Hunt PW, Lynch SV, McCune JM: Dysbiosis of the gut microbiota is associated with HIV disease progression and tryptophan catabolism. Sci Transl Med 2013, 5:193ra91. https://doi.org/10.1126/scitranslmed.3006438

62. Gori A, Tincati C, Rizzardini G, Torti C, Quirino T, Haarman M, Ben Amor K, van Schaik J, Vriesema A, Knol J, Marchetti G, Welling G, Clerici M J: Early impairment of gut function and gut flora supporting a role for alteration of gastrointestinal mucosa in human immunodeficiency virus pathogenesis. Clin Microbiol 2008, 46:757-8. https://doi.org/10.1128/JCM.01729-07

63. Seksik P, Rigottier-Gois L, Gramet $G$, Sutren $M$, Pochart $P$, Marteau P, Jian R, Doré J: Alterations of the dominant faecal bacterial groups in patients with Crohn's disease of the colon. Gut 2003, 52:237-242. https://doi.org/10.1136/gut.52.2.237

64. Finegold SM: Desulfovibrio species are potentially important in regressive autism. Med Hypotheses 2011, 77:270-4. https://doi.org/10.1016/j.mehy.2011.04.032

65. Hildebrandt MA, Hoffmann C, Sherrill-Mix SA, Keilbaugh SA, Hamady M, Chen YY, Knight R, Ahima RS, Bushman F, Wu GD: High-fat diet determines the composition of the murine gut microbiome independently of obesity. Gastroenterology 2009, 137: 1716-24.e1-2. https://doi.org/10.1053/j.gastro.2009.08.042 
66. Murri M, Leiva I, Gomez-Zumaquero JM, Tinahones FJ, Cardona F, Soriguer F, Queipo-Ortuño MI: Gut microbiota in children with type 1 diabetes differs from that in healthy children: a case-control study. BMC Med 2013, 11:46. https://doi.org/10.1186/1741-7015-11-46

67. Yatsunenko T, Rey FE, Manary MJ, Trehan I, DominguezBello MG, Contreras M, Magris M, Hidalgo G, Baldassano RN, Anokhin AP, Heath AC, Warner B, Reeder J, Kuczynski J, Caporaso JG, Lozupone CA, Lauber C, Clemente JC, Knights D, Knight R, Gordon Jl: Human gut microbiome viewed across age and geography. Nature 2012, 486:222-227. https://doi.org/10.1038/nature11053

68. Heimesaat MM, Fischer A, Siegmund B, Batra A, Loddenkemper C, Liesenfeld O, Blaut M, Gobel UB, Schumann RR, Bereswill S: Shifts towards pro-inflammatory intestinal bacteria aggravate acute murine colitis and ileitis via toll-like-receptor signaling. Int. J. Med. Microbiol 2007, 29743:81-82. https://doi.org/10.1556/EuJMI.1.2011.4.6

69. Kamada N, Hisamatsu T, Okamoto S, Sato T, Matsuoka K, Arai K, Nakai T, Hasegawa A, Inoue N, Watanabe N, Akagawa KS, Hibi T: Abnormally differentiated subsets of intestinal macrophage play a key role in Th1-dominant chronic colitis through excess production of IL-12 and IL-23 in response to bacteria. J Immunol 2005, 175:6900-6908. https://doi.org/10.4049/jimmunol.175.10.6900

70. Yeoh N, Burton JP, Suppiah P, Reid G, Stebbings S: The role of the microbiome in rheumatic diseases. Curr Rheumatol Rep 2013,15:314. https://doi.org/10.1007/s11926-012-0314-y

71. Rinninella E, Raoul P, Cintoni M, Franceschi F, Miggiano G, Gasbarrini A, Mele M: What is the healthy gut microbiota composition? A changing ecosystem across age, environment, diet, and diseases. Microorganisms 2019, 7:14. https://doi.org/10.3390/microorganisms701001

72. Musilova S, Rada V, Vlkova E, Bunesova V: Beneficial effects of human milk oligosaccharides on gut microbiota. Benef Microbes 2014, 3:273.

https://doi.org/10.3920/BM2013.0080

73. Woodmansey EJ: Intestinal bacteria and ageing. J Appl Microbiol 2007, 102:1178-1186. https://doi.org/10.1111/j.1365-2672.2007.03400.x

74. Guetterman HM, Huey SL, Knight R, Fox AM, Mehta S, Finkelstein JL: Vitamin B-12 and the gastrointestinal microbiome: a systematic review. Adv Nutr 2021. https://doi.org/10.1093/advances/nmab123
75. Ramirez J, Guarner F, Bustos Fernandez L, Maruy A, Sdepanian VL, Cohen $\mathrm{H}$ : Antibiotics as major disruptors of gut microbiota. Front Cell Infect Microbiol 2020, 10:572912. https://doi.org/10.3389/fcimb.2020.572912

76. Merra G, Noce A, Marrone G, Cintoni M, Tarsitano MG, Capacci A, De Lorenzo A: Influence of mediterranean diet on human gut microbiota. Nutrients 2020,13:7. https://doi.org/10.3390/nu13010007

77. Marcobal A, Sonnenburg JL: Human milk oligosaccharide consumption by intestinal microbiota. Clin Microbiol Infect 2012, 4: 12-15. https://doi.org/10.1111/j.1469$\underline{0691.2012 .03863 . x}$

78. Yang X, Darko K, O, Huang Y, He C, Yang H, He S, Li J, Li J, Hocher B, Yin Y: Resistant starch regulates gut microbiota: structure, biochemistry and cell signalling. Cell Physiol Biochem 2017, 42:306-318. https://doi.org/10.1159/000477386

79. Mathieu S, Touvrey-Loiodice M, Poulet L, Drouillard S, Vincentelli R, Henrissat B, Skjåk-Bræk G, Helbert W: Ancient acquisition of "alginate utilization loci" by human gut $\begin{array}{llll}\text { microbiota. Sci } & \text { Rep. } & \text { 8:8075. }\end{array}$ https://doi.org/10.1038/s41598-018-26104-1

80. McIntosh GH, Noakes M, Royle PJ, Foster PR: Whole-grain rye and wheat foods and markers of bowel health in overweight middle-aged men. Am J Clin Nutr 2003, 77:967974. https://doi.org/10.1093/ajcn/77.4.967

81. Hamaker BR, Tuncil YE: A Perspective on the complexity of dietary fiber structures and their potential effect on the gut microbiota. J Mol.Biol 2014, 426:3838-3850. https://doi.org/10.1016/j.jmb.2014.07.028

82. Daïen $\mathrm{Cl}$, Pinget GV, Tan JK, Macia L: Detrimental impact of microbiota-accessible carbohydrate-deprived diet on gut and immune homeostasis: An overview. Front immunol 2017, 8:548. https://doi.org/10.3389/fimmu.2017.00548

83. Tan J, McKenzie C, Vuillermin PJ, Goverse G, Vinuesa CG, Mebius RE, Macia L, Mackay CR: Dietary fiber and bacterial SCFA enhance oral tolerance and protect against food allergy through diverse cellular pathways. Cell Reports 2016, 15: 2809-2824.

https://doi.org/10.1016/j.celrep.2016.05.047

84. Schirmer $M$, Smeekens SP, Vlamakis $H$, Jaeger $M$, Oosting $M$, Franzosa EA, Ter Horst R, Jansen T, Jacobs L, Bonder MJ, Kurilshikov A, Fu J, Joosten LAB, Zhernakova A, Huttenhower C, Wijmenga C, Netea MG, Xavier RJ: Linking the human gut microbiome to inflammatory cytokine production capacity. Cell 2016, 167:1125-1136.

https://doi.org/10.1016/j.cell.2016.10.020 
85. Sonnenburg ED, Smits SA, Tikhonov M, Higginbottom SK, Wingreen NS, Sonnenburg JL: Diet-induced extinctions in the gut microbiota compound over generations. Nature 2016, 529:212-215

https://doi.org/10.1038/nature16504529:7585

86. Eid N, Enani S, Walton G, Corona G, Costabile A, Gibson G, Rowland I, Spencer JP: The impact of date palm fruits and their component polyphenols, on gut microbial ecology, bacterial metabolites and colon cancer cell proliferation. J Nutr Sci 2014, 8;3:e46. https://doi.org/10.1017/jns.2014.16

87. Terada A, Hara H, Mitsuoka T: Effect of dietary alginate on the faecal microbiota and faecal metabolic activity in humans. Microb Ecol Health Dis 1995, 8:259-266. https://doi.org/10.3109/08910609509140105

88. Ho Do M, Seo YS, Park HY: Polysaccharides: bowel health and gut microbiota. Crit Rev Food Sci Nutr 2018, 61:1212-1224. https://doi.org/10.1080/10408398.2020.1755949

89. Li M, Shang $Q$, Li G, Wang X, \& Yu G: Degradation of marine algae-derived carbohydrates by bacteroidetes isolated from human gut microbiota. Marine Drugs 2017, 15: 92. https://doi.org/10.3390/md15040092

90. Katarzyna Ś, Janusz K, Renata B and Kamila J:Resistant dextrins as prebiotic, carbohydrates - comprehensive studies on glycobiology and glycotechnology. IntechOpen 2012. https://www.intechopen.com/chapters/41117

91. Suez J, Korem T, Zeevi D, Zilberman-Schapira G, Thaiss CA, Maza O, Israeli D, Zmora N, Gilad S, Weinberger A, Kuperman Y, Harmelin A, Kolodkin-Gal I, Shapiro H, Halpern Z, Segal E, Elinav E: Artificial sweeteners induce glucose intolerance by altering the gut microbiota. Nature 2014, 514:181-186.

92. Oliphant K, Allen-Vercoe E, Macronutrient metabolism by the human gut microbiome: major fermentation byproducts and their impact on host health. Microbiome 2019, 7. https://doi.org/10.1186/s40168-019-0704-8

93. Singh RK, Chang HW, Yan D, Lee KM, Ucmak D, Wong K, Abrouk M, Farahnik B, Nakamura M, Zhu TH, Bhutani T, Liao $\mathrm{W}$ : Influence of diet on the gut microbiome and implications for human health. J Transl Med 2017 15:1. https://doi.org/10.1186/s12967-017-1175-y

94. Tomova A, Bukovsky I, Rembert E, Yonas W, Alwarith J, Barnard ND and Kahleova $\mathrm{H}$ : The effects of vegetarian and vegan diets on gut microbiota. Front Nutr 2019, 6:47. https://doi.org/10.3389/fnut.2019.00047

95. Sánchez-Moya T, López-Nicolás R, Planes D, GonzálezBermúdez CA, Ros-Berruezo G, Frontela-Saseta C: In vitro modulation of gut microbiota by whey protein to preserve intestinal health. Food Funct 2017,8:3053-3063. https://doi.org/10.1039/c7fo00197e

96. Usta-Gorgun B, Yilmaz-Ersan L: Short-chain fatty acids production by Bifidobacterium species in the presence of salep. Electron J Biotechnol 2020, 47:29-35. https://doi.org/10.1016/j.ejbt.2020.06.004

97. Schoeler M, Caesar R: Dietary lipids, gut microbiota and lipid metabolism. Rev Endocr Metab Disord 2019, 20:461-472. https://doi.org/10.1007/s11154-019-09512-0

98. Wolters M, Ahrens J, Romaní-Pérez M, Watkins C, Sanz Y, Benítez-Páez A, Stanton C, Günther K: Dietary fat, the gut microbiota, and metabolic health - A systematic review conducted within the MyNewGut project. Clin Nutr 2019, 38:2504-2520. https://doi.org/10.1016/j.clnu.2018.12.024

99. Li H, Zhu Y, Zhao F: Fish oil, lard and soybean oil differentially shape gut microbiota of middle-aged rats. Sci Rep, 2017, 7:826. https://doi.org/10.1038/s41598-017-00969-0

100. Hervert-Hernández D, Goñi I: Dietary polyphenols and human gut microbiota: a review. Food Rev Int 2011, 27:154169. https://doi.org/10.1080/87559129.2010.535233

101. Comalada M, Camuesco D, Sierra S, Ballester I, Xaus J, Gálvez $\mathrm{J}$, Zarzuelo A: In vivo quercitrin anti-inflammatory effect involves release of quercetin, which inhibits inflammation through down-regulation of the NF-kappaB pathway. Eur J Immunol 2005,35:584-592. https://doi.org/10.1002/eji.200425778

102. Tzounis $X$, Vulevic J, Kuhnle GG, George T, Leonczak J, Gibson GR, Kwik-Uribe C, Spencer JP: Flavanol monomer-induced changes to the human faecal microflora. Br J Nutr, 2008, 99:782-792.

https://doi.org/10.1017/S0007114507853384

103. Laparra JM, Sanz Y: Interactions of gut microbiota with functional food components and nutraceuticals. Pharmacol Res 2010, 61:219-225. https://doi.org10.1016/j.phrs.2009.11.001

104. Lee HC, Jenner AM, Low CS, Lee YK: Effect of tea phenolics and their aromatic fecal bacterial metabolites on intestinal microbiota. Res Microbiol 2006,157:876-884. https://doi.org10.1016/j.resmic.2006.07.004

105. Larrosa M, Yañéz-Gascón MJ, Selma MV, González-Sarrías A, Toti S, Cerón JJ, Tomás-Barberán F, Dolara P, Espín JC: Effect of a low dose of dietary resveratrol on colon microbiota, inflammation and tissue damage in a DSS-induced colitis rat model. J Agric Food Chem 2009, 57:2211-2020. https://doi.org/10.1021/jf803638d 
106. Puupponen-Pimiä R, Nohynek L, Hartmann-Schmidlin S, Kähkönen $M$, Heinonen $M$, Määttä-Riihinen $K$, OksmanCaldentey KM: Berry phenolics selectively inhibit the growth of intestinal pathogens. J Appl Microbiol 2005, 98:991-1000. https://doi.org/10.1111/j.1365-2672.2005.02547.x
107. Ito $Y$, Ichikawa T, Iwai T, Saegusa $Y$, Ikezawa T, Goso Y: Effects of tea catechins on the gastrointestinal mucosa in rats. J Agric Food Chem 2008,56:12122-12126.

https://doi.org/10.1021/jf802142n 